\title{
Fluorinated Hybrid Polymers by Copolymerization of Trialkylsilyl Methacrylate with Fluoroalkyl Methacrylate
}

\author{
Hirotada FujIWARA, Tadashi Narita, ${ }^{\dagger}$ Hiroshi Hamana, ${ }^{*}$ and Koichi ShImIzU* \\ Department of Materials Science and Engineering, Graduate School of Engineering, Saitama Institute of Technology, \\ 1690 Fusaiji, Okabe, Saitama 369-0293, Japan \\ * Department of Applied Chemistry, Faculty of Engineering, Saitama Institute of Technology, \\ 1690 Fusaiji, Okabe, Saitama 369-0293, Japan
}

(Received April 8, 2002; Accepted July 4, 2002)

\begin{abstract}
KEY WORDS Tributylsilyl Methacrylate / 2,2,2-Trifluoroethyl Methacrylate / 1-Trifluoromethyl2,2,2-trifluoroethyl Methacrylate / Radical Copolymerization / Anionic Copolymerization / Contact Angle /
\end{abstract}

The easiest way to obtain fluorinated hybrid polymers possessing silicone atoms might be vinyl copolymerization of fluorinated vinyl monomers with vinyl monomers possessing silyl groups as substituents. To prepare fluorinated hybrid polymers bearing alkylsilyl groups, copolymerization of fluoroalkyl methacrylates with alkylsilyl methacrylates was investigated, and the surface character of the copolymers was examined by measurement of the contact angle with water and methanol. Radical copolymerization of monomers similar in structure such as styrene with 1,3-butadiene produces random copolymer. By anionic copolymerization, 1,3-butadiene is preferentially incorporated into the copolymer at the early stage of the reaction and styrene is mainly incorporated after the butadiene concentration decreases. A copolymer of block-type structure is then yielded. ${ }^{1,2}$ Different characteristics may be expected between copolymers derived from radical and anionic copolymerization even if the monomer feed ratios of copolymerization reactions are equal and copolymer yields are quantitative since sequential distributions of each monomer units in copolymer are usually different. This paper reports the copolymerization reactivity of tributylsilyl methacrylate (NBSM) with 2,2,2-trifluoroethyl methacrylate (TFEM) or 1trifluoromethyl-2,2,2-trifluoroethyl methacrylate (HxFIM) initiated with benzoyl peroxide (BPO) or lithium butyldiethylzincate $\left(\mathrm{LiZnBuEt}_{2}\right)$. Copolymers would be easily obtained since the $Q, e$-values of these monomers are; NBSM: $0.39,0.61 ; 3$ TFEM: $1.13,0.98,{ }^{4}$ and HxFIM: $1.38,1.30,{ }^{4}$ respectively (Scheme 1). The measurements of contact angle of copolymers obtained was also carried out.

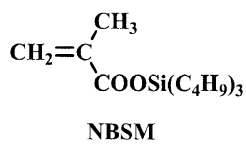<smiles>C=C(C)C(=O)OCC(F)(F)F</smiles><smiles>C=C(C)C(=O)OC(C)(C)C</smiles>

Scheme 1.

Though radical copolymerization reactivity of fluoroalkyl acrylates with alkyl acrylates has been reported, ${ }^{5}$ no report on the copolymerization of fluoroalkyl (meth)acrylates with silylalkyl (meth)acrylates is available.

\section{EXPERIMENTAL}

Tributylsilyl methacrylate (NBSM) (from YUKI GOSEI KOGYO CO., LTD.) was refluxed over calcium hydride and distilled under reduced pressure; bp $126^{\circ} \mathrm{C} / 4 \mathrm{mmHg}$. 2,2,2-Trifluoroethyl methacrylate (TFEM) or 1-trifluoromethyl-2,2,2-trifluoroethyl methacrylate (HxFIM) (from Central Glass Co., Ltd.) were refluxed over calcium hydride and distilled; bp TFEM: $59^{\circ} \mathrm{C} / 100 \mathrm{mmHg}$; HxFIM: $99^{\circ} \mathrm{C} / 760 \mathrm{mmHg}$. The monomers were stored under a nitrogen atmosphere. Benzoyl peroxide (BPO) was recrystallized from chloroform. Radical copolymerizations of NBSM $\left(\mathrm{M}_{1}\right)$ and fluoroalkyl methacrylates $\left(\mathrm{M}_{2}\right)$ were carried out in bulk with sealed tube under nitrogen atmosphere at $80^{\circ} \mathrm{C}$ initiated by BPO $(1.0 \mathrm{~mol} \%)$. Anionic copolymerizations were carried out under nitrogen atmosphere at $0^{\circ} \mathrm{C}$ initiated with $\mathrm{LiZnBuEt}_{2}(0.5 \mathrm{~mol} \%)$

${ }^{\dagger}$ To whom all correspondence should be addressed (Phone: +81-48-585-6836, E-mail: narita@sit.ac.jp). 
Table I. Copolymerization of tributylsilyl methacrylate $\left(\mathrm{M}_{1}\right)$ with hexafluoroisopropyl methacrylate initiated with $\mathrm{LiZnBuEt}_{2}$ at $0^{\circ} \mathrm{C}$

\begin{tabular}{|c|c|c|c|c|c|}
\hline$\frac{\mathrm{NBSM}}{\mathrm{mmol}}$ & $\frac{\mathrm{HxFIM}}{\mathrm{mmol}}$ & $\frac{\text { Time }}{\mathrm{h}}$ & $\frac{\text { Yield }}{w t \%}$ & $\frac{\left[\mathrm{M}_{1}\right] \text { in monomer }}{\mathrm{mol} \%}$ & $\frac{\left[\mathrm{M}_{1}\right] \text { in copolymer }}{\mathrm{mol} \%}$ \\
\hline 2 & 18 & 2.0 & 10.9 & 10 & 0.29 \\
\hline 4 & 16 & 3.0 & 7.22 & 20 & 0.31 \\
\hline 6 & 14 & 3.5 & 10.4 & 30 & 0.55 \\
\hline 8 & 12 & 4.5 & 0.62 & 40 & 2.17 \\
\hline 10 & 10 & 4.5 & 1.18 & 50 & 28.1 \\
\hline 10 & 10 & 4.5 & 0.46 & 50 & 35.7 \\
\hline 12 & 8 & 5.0 & 0.11 & 60 & 23.5 \\
\hline 14 & 6 & 6.0 & 0.89 & 70 & 30.3 \\
\hline 16 & 4 & 6.0 & 2.62 & 80 & 56.6 \\
\hline 16 & 4 & 6.0 & 1.80 & 80 & 71.3 \\
\hline 18 & 2 & 6.5 & 1.97 & 90 & 69.6 \\
\hline 18 & 2 & 6.5 & 2.06 & 90 & 86.0 \\
\hline
\end{tabular}

in sealed tube. $\mathrm{LiZnBuEt}_{2}$ was synthesized by equimolar reaction of butyllithium with diethylzinc in tetrahydrofuran (THF) as solvent. Commercial hexane solution of butyllithium was used after determination of the concentration by alkalimetry. THF was purified by the usual method. The copolymer was isolated by reprecipitation in methanol, and dried to constant weight. Copolymer composition of each monomer unit in copolymer was calculated from ${ }^{1} \mathrm{H}$ NMR measurement and elemental analysis. ${ }^{1} \mathrm{H}$ and ${ }^{13} \mathrm{C}$ NMR were measured with a JEOL JNM-ECP500. Monomer reactivity ratios were determined by the curve-fitting method. Contact angle was measured by the liquid drop method. After a copolymer sample was spin-coated followed by removing THF on a hot-plate, measurements were carried out five times at different spots of the polymer surface. The procedure was repeated twice and average values were calculated. No remarkably different values were obtained by the contact angle measurements after keeping the sample in saturated water vapor.

\section{RESULTS AND DISCUSSION}

To estimate the sequential distribution of monomer units in copolymers, monomer reactivity of NBSM with TFEM and NBSM with HxFIM under radical and anionic polymerization conditions was studied. Copolymerizations were carried out with BPO as radical initiator and $\mathrm{LiZnBuEt}_{2}$ as anionic initiator. Ate complexes such as calcium tetraethylzincate and strontium tetraethylzincate are well-known initiators for the polymerization of alkyl crotonates which are hardly polymerized with organolithium and Grignard reagents. ${ }^{6,7}$ Ate complexes react preferentially with the vinyl group rather than carbonyl group of $\alpha, \beta$ unsaturated carbonyl compounds. The experimental results of anionic copolymerization of NBSM with $\mathrm{Hx}-$

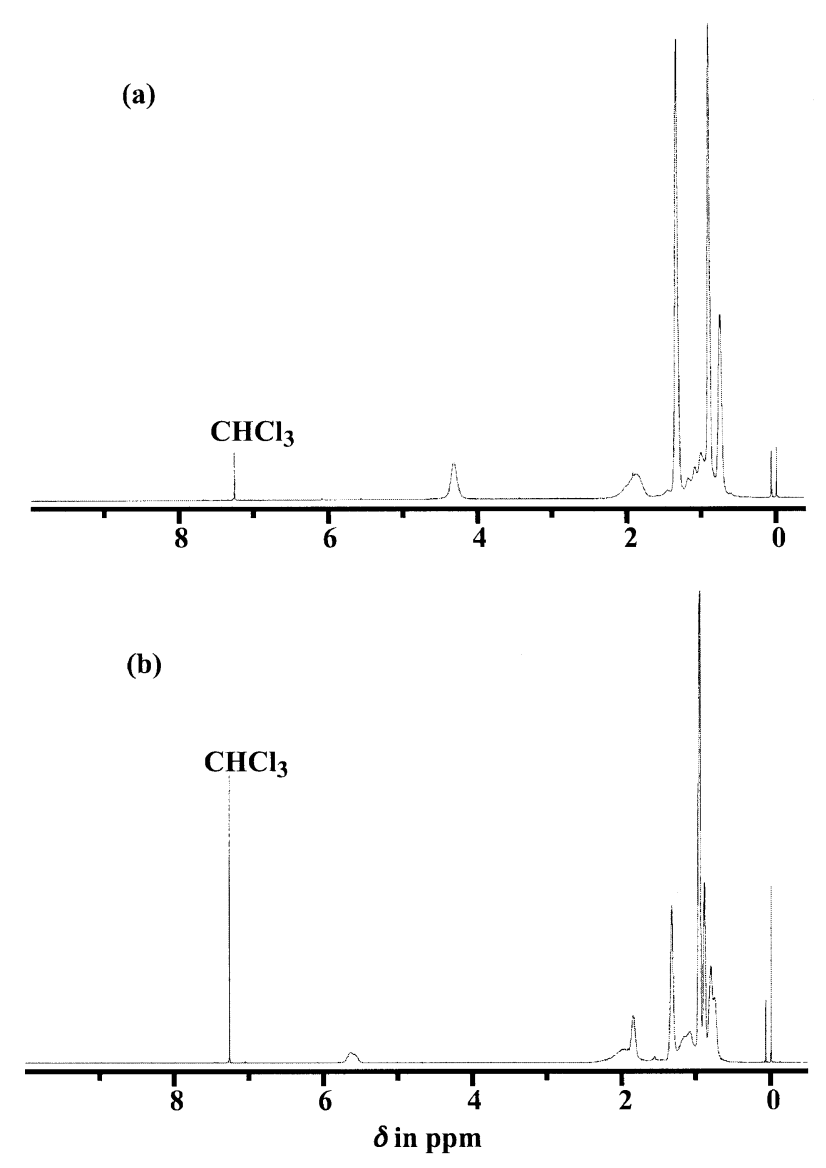

Figure 1. ${ }^{1} \mathrm{H}$ NMR of copolymer of NBSM with TFEM (a) and NBSM with HxFIM (b).

FIM are summarized in Table I. The copolymerization reaction was ceased less than $10 \%$ yields of copolymers.

The composition of each monomer unit in copolymer was calculated from measurement of ${ }^{1} \mathrm{H}$ NMR and elemental analysis. ${ }^{1} \mathrm{H}$ NMR spectra of copolymers of NBSM with TFEM and NBSM with HxFIM are shown in Figure 1. A peak around $4.1 \mathrm{ppm}$ in Figure 1(a) is assignable to $\mathrm{CF}_{3} \underline{\mathrm{C}}_{2}$ of TFEM moiety in copolymer and absorption from 0.7 to $1.3 \mathrm{ppm}$ is assigned to 
Table II. Monomer reactivity of tributylsilyl methacrylate $\left(\mathrm{M}_{1}\right)$ with fluoroalkyl methacrylate $\left(\mathrm{M}_{2}\right)$

\begin{tabular}{clccc}
\hline $\mathrm{M}_{2}$ & Initiator & $\mathrm{r}_{1}$ & $\mathrm{r}_{2}$ & $\mathrm{r}_{1} \mathrm{r}_{2}$ \\
\hline TFEM & BPO & 0.47 & 0.95 & 0.45 \\
TFEM & LiZnBuEt $_{2}$ & 0.38 & 1.01 & 0.38 \\
HxFIM & BPO & 0.44 & 0.75 & 0.33 \\
HxFIM & LiZnBuEt $_{2}$ & 0.78 & 6.41 & 2.93 \\
\hline
\end{tabular}

Table III. Contact angles of copolymers

\begin{tabular}{|c|c|c|c|c|c|c|}
\hline \multirow{2}{*}{ Copolymer $^{\mathrm{a}}$} & \multirow{2}{*}{ Initiator } & \multirow{2}{*}{$\frac{M_{\mathrm{n}}{ }^{\mathrm{b}}}{\times 10^{5}}$} & \multirow{2}{*}{$M_{\mathrm{w}} / M_{\mathrm{n}}^{\mathrm{b}}$} & \multirow{2}{*}{$\begin{array}{c}\text { Film }^{\mathrm{c}} \\
\text { Thickness } \\
\mu \mathrm{m}\end{array}$} & \multicolumn{2}{|c|}{$\begin{array}{l}\text { Contact } \\
\text { Angle }^{\mathrm{d}}\end{array}$} \\
\hline & & & & & $\mathrm{H}_{2} \mathrm{O}$ & $\mathrm{CH}_{3} \mathrm{OH}$ \\
\hline NBSM-co-TFEM & $\mathrm{BPO}$ & 0.9 & 1.8 & 0.81 & $104.3^{\circ}$ & $28.2^{\circ}$ \\
\hline NBSM-co-TFEM & $\mathrm{LiZnBuEt}_{2}$ & 1.6 & 1.8 & 0.70 & $105.8^{\circ}$ & $22.1^{\circ}$ \\
\hline NBSM-co-HxFIM & $\mathrm{BPO}$ & 0.5 & 1.9 & 1.45 & $105.2^{\circ}$ & $25.2^{\circ}$ \\
\hline NBSM-co-HxFIM & $\mathrm{LiZnBuEt}_{2}$ & 1.4 & 1.6 & 1.90 & $108.6^{\circ}$ & $36.3^{\circ}$ \\
\hline
\end{tabular}

${ }^{\mathrm{a}} M_{1}: M_{2}=50: 50 .{ }^{\mathrm{b}} \mathrm{GPC}$ based on polystyrene standards, eluent THF. ${ }^{\mathrm{c}} \mathrm{THF}$ solv. ( $15 \mathrm{wt} \%$ ), spin coat $\left(800 \mathrm{rpm}\right.$ for $10 \mathrm{sec}$, later $2000 \mathrm{rpm}$ for $40 \mathrm{sec}$ ), drying at $80^{\circ} \mathrm{C}$ for 20 min. ${ }^{\mathrm{d}}$ Liquid drop method.

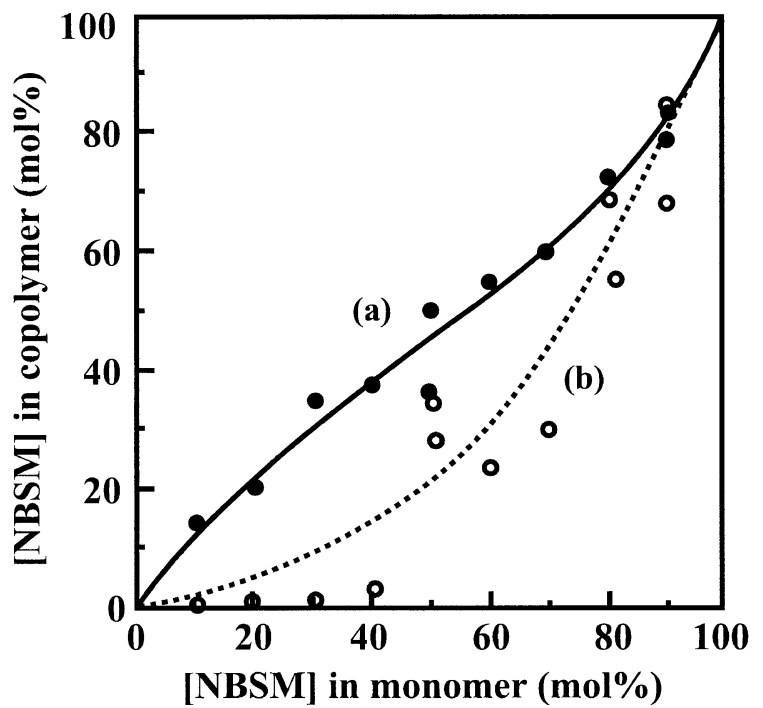

Figure 2. Copolymer composition curves of NBSM with $\mathrm{Hx}$ FIM by BPO (a) and $\mathrm{LiZnC}_{4} \mathrm{H}_{9}\left(\mathrm{C}_{2} \mathrm{H}_{5}\right)_{2}$ (b).

butyl hydrogens of NBSM moiety in copolymer. The peak around $5.7 \mathrm{ppm}$ in Figure $1(\mathrm{~b})$ is assignable to $\left(\mathrm{CF}_{3}\right)_{2} \mathrm{CH}$ of HxFIM moiety in copolymer and absorption from 0.7 to $1.3 \mathrm{ppm}$ is assigned to butyl hydrogens of NBSM moiety in copolymer. Turbidity measurements showed that the products were copolymers because of no indication that the products are polymer blends of poly(NBSM) and poly(TFEM).

A typical copolymer composition curve is shown in Figure 2. Similar reproducibility of other copolymer composition curves was obtained. Resulted monomer reactivity ratios are summarized in Table II. Random copolymers are found to be produced in radical copolymerizations of NBSM with TFEM and NBSM with HxFIM, and in anionic copolymerization of NBSM with
TFEM since the monomer reactivity ratios are smaller than 1.0, and $r_{1} r_{2}$ values are also smaller than 1.0. Block-type copolymer is obtained in anionic copolymerization of NBSM with HxFIM since $r_{2}$ is as high as 6.41 and $r_{1} r_{2}$ is also larger than 1.0. HxFIM molecules are, therefore, incorporated preferentially into copolymer chain at an early stage of the reaction and NBSM molecules are incorporated after the concentration of HxFIM decreases. Higher anionic polymerization reactivity of HxFIM as demonstrated by large $e$-value might be amplified in the copolymerization system. The block-type copolymer is then found to be produced under anionic condition.

The characteristics of the copolymer obtained from radical and anionic copolymerization conditions might be different since the sequential distribution of each monomer units in the copolymers is found to be different. Surface character might show clearly the differences of the sequential distribution of monomer units in the copolymers. The content of fluorine atoms on the surface might be higher in block-type copolymers and the surface character should be influenced by the content of fluorine atoms. ${ }^{5}$ Contact angle measurements of the copolymers are summarized in Table III. Copolymer compositions of the samples were almost equal since the copolymers were synthesized by equimolar feed of each monomer with quantitative yields of copolymers. Although contact angles of the copolymers with water show little difference, the contact angles with methanol indicate large differences. Copolymer of NBSM with HxFIM produced under anionic copolymerization condition shows large contact angle which might be reflection of the block-type structure of copolymer. 


\section{REFERENCES}

1. I. Kuntz, J. Polymer Sci., 54, 569 (1961).

2. F. A. Bovey, F. F. Abere, G. B. Rathmann, and C. L. Sandberg, J. Polym. Sci., 15, 520 (1955).

3. H. Fujiwara, T. Narita, and H. Hamana, Polym. J., 33, 102 (2001).
4. T. Narita, T. Hagiwara, and H. Hamana, Makromol. Chem., Rapid Commun., 6, 5 (1985).

5. M. Morita, H. Ogisu, and M. Kubo, J. Appl., Polym. Sci., 73, 1741 (1999).

6. T. Narita, T. Hagiwara, H. Hamana, and M. Goto, Makromol. Chem., 187, 731 (1986).

7. T. Tsuruta, T. Makimoto, and K. Tanabe, Makromol. Chem., 114, 182 (1968). 